\title{
THE PARTICLE POLLUTION IN FRANCE IN DECEMBRE 2016: EXCEPTIONAL OR NORMAL SITUATION?
}

\author{
Z. NOUACEUR ${ }^{1}$
}

\begin{abstract}
The particle pollution in France in December 2016: exceptional or normal situation? The type of cold anti-cyclonic winter weather represents a climatic situation that reinforces the stability of the low atmospheric layers. It creates ideal conditions for the occurrence of temperature inversions (the air is cooler in the lower layers than in the upper layers). These phenomena favor the blockage of pollutant particles and accentuate their concentration in atmosphere. In recent years, the alerts to pollution by particles have multiplied in France. This situation is new, because of the changed measurement protocol in January 2007 and by lowering the alert and information thresholds since January 2012. The pollution alerts which multiplied during the month of December 2016 generated a great political debate on this subject. The alternating traffic has been adopted twice in Paris. A "Crit'Air" vignette issued to the clean cars is now mandatory from 15 January 2017 to circulate in Paris. The present paper aims to study this new situation from the December 2016 pollution episode.
\end{abstract}

Keywords: particle pollution, PM10, France

\section{INTRODUCTION}

The very high content of volatile particles in the urban atmosphere is responsible for serious human health problems that sometimes may even trigger the death of the most fragile people (Laurence et al, 2009, Corso et al, 2015, Pascal et al, 2016). These pollutants belong to the category of atmospheric aerosols representing atmospheric solid or liquid particulate matter, excluding the drops of water and the ice crystals in clouds and fog (WMO, 1983). These compounds have a considerable role on the global radiative balance of the Earth (Paolo et al, 2003). The eruption of the Pinatubo volcano triggered the decrease of the Earth's average temperature by 1 to $1.5^{\circ} \mathrm{C}$, for almost two years.

The sources of particle emission in the region of France in winter are multiple:

- road traffic (diesel cars contribute significantly to this type of pollution);

- the burning of biomass related to stove heating, sawdust boilers, agricultural fires and garden fires; this source represents a very important part of the particular pollution (www.cnrs.fr/alpes, 2007), evaluated by the European research programme on pollution by carbonated compounds, "CARBOSOL", to between "50 and $70 \%$ " (Legrand \& al., 2007);

- the industrial source.

1 UMR IDÉES CNRS 6226, Rouen University, 1 Rue Thomas Becket 76821, Mont Saint-Aignan Cedex France, zeineddine.nouaceur@univ-rouen.fr 


\section{DATA AND RESULTS}

The data related to pollution used for this study were collected by the air quality monitoring network "Air Parif" from the measurement stations: La Défense, Champs - Elysées, Opéra, Boulevard, Haussman, Paris centre.

The hourly pollution data were treated statistically. The average of the measurement stations was taken into account as representative for the regional average pollution level. The climat Data was provided from Meteo-France (2017)

During the month of December 2016, the weather situation in France was dominated by generalized anticyclonic conditions characterized by a large precipitation deficit, strong sunshine and low winds. The map (Fig. 1) is showing an average pressure of (1027) between the first and twenty December centered on France and the southern Europe.

This air barrier blocks the passage of the perturbations from the west. In Parisian region, the weather is dominated by an increase of the atmospheric pressures, which reach a mean of 1030.30. The temperatures are relatively cold, the sunshine is significant and the fogs, sometimes freezing fogs, are persistent. This particular situation favors the occurrence of temperature inversions in the low atmospheric layers. Measurements by radiosonding at meteorological station "Trappes" situated near the city of Paris, on the night of December 5-6, indicated a temperature rise of about 10 degrees over the first 150 meters of the troposphere and the lowest layers of the atmosphere. This situation shows the conditions of thermal inversion which prevents the diffusion of the pollutants and favored air pollution. The difference in minimum temperatures observed on Tuesday 6 December in the early morning hours between the top of the Eiffel Tower $\left(8^{\circ} \mathrm{C}\right)$ and ParisMontsouris (station situated in the center) $\left(2^{\circ} \mathrm{C}\right)$ is 6 degrees more on the ground than at about $300 \mathrm{~m}$ altitude this shows also these stable atmospheric conditions.

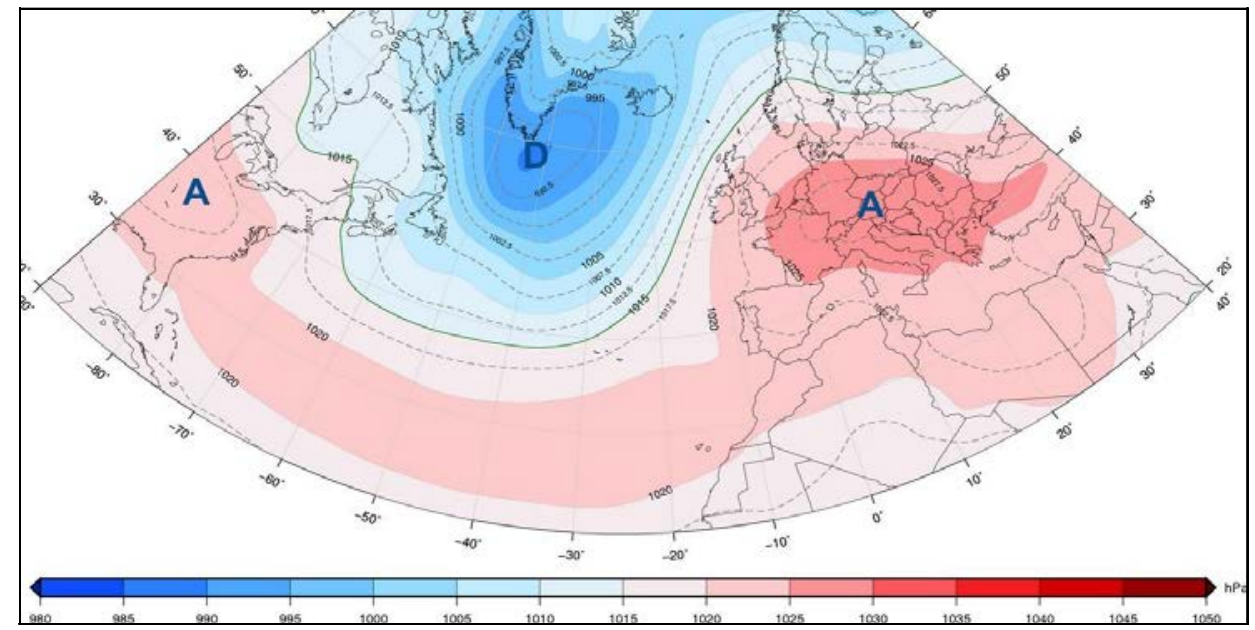

Fig. 1. Pressure at sea level (average from 1 to 20 December) (Meteo-France, http://www.meteofrance.com) 
A very significant pollution affected the major French cities in December 2016. During this period, several pollution alerts were triggered, notably in Normandy, Ile de France, Rhône-Alpes and Aquitaine. The maps in Figure 2 show the daily maximum concentrations recorded on December 2 and 6 throughout the country. These values exceeded $120 \mu \mathrm{g} / \mathrm{m}^{3}$ (one-millionth of a gram per cubic meter air) in Paris, Rouen, Lyon, Marseille and Grenoble. This situation was widely relayed by the media for several days and became a major concern for politicians who preparing the future presidential elections of May 2017.

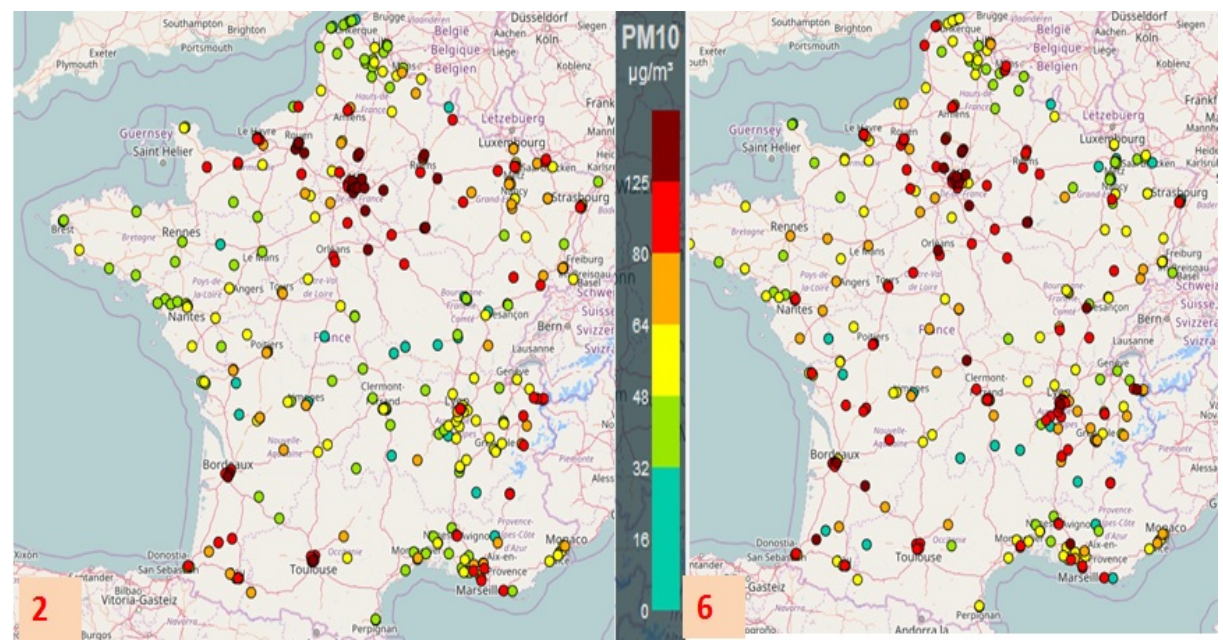

Fig. 2. Maximum daily concentration of PM10 (Decembre 2016, 2 and 6)

(Data: http://www2.prevair.org/)

On the level of the air quality monitoring in Paris, the information and recommendation threshold (for PM10) for sensitive people in force since 2012 (50 $\mu \mathrm{g} / \mathrm{m} 3$ ) were exceeded four time (5, 8, 15 and 30 December). The alert exceeding the threshold of $80 \mu \mathrm{g} / \mathrm{m} 3$ ) was triggered on 1, 2, 6 and 7th December 2016 (Fig. 3).

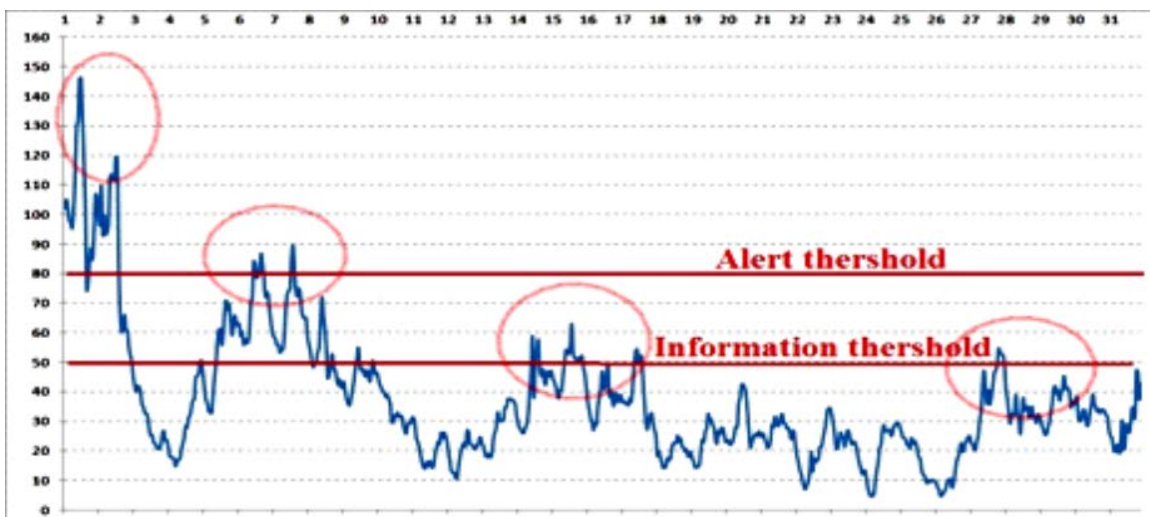

Fig. 3. Evolution of the hourly PM10 ( $\mu \mathrm{g} / \mathrm{m} 3)$ concentrations between 1st and 31nd December 2016 (Data: http://www.airparif.asso.fr/) 
The alert is activated on 1st December following an average daily concentration exceeding a mean hourly of $105 \mu \mathrm{g} / \mathrm{m} 3$. The average on 2nd December reached 84,69 $\mu \mathrm{g} / \mathrm{m} 3$. On 7th December, the high value $113 \mu \mathrm{g} / \mathrm{m} 3$ was recorded in Champs - Elysées at 2 PM.

\section{DISCUSSION}

A reform of the measurement methods and information \& alert thresholds in two steps.

\subsection{A new measurement protocol adopted in 2007 in France}

One of the first methods used to quantify the atmospheric particulate (PM10 and PM2.5) is the so-called black smoke method. Using the mark left by these particles on a filter paper, the content of atmospheric particles is evaluated. A blackness index indicate the concentration using the international standardized calibration curve proposed by OECD (the Organization for Economic Cooperation and Development). Better automatic methods complete this last technique. The TEOM (Tapered Element Oscillating Microbalance) method permits a continual measurement thanks to vibration frequency variations of an oscillating element on which the particles are deposited. The microbalance is heated at $50^{\circ} \mathrm{C}$ to avoid the condensation of the water vapors contained in the air. This procedure can, however, trigger a volatilization of certain components that entail an underestimation of the concentration measured (Allen \& al., 1997, Ayers \& al., 1999). The TEOM-FDMS (Filter Dynamics Measurement System) method has been developed to take care of the volatilization of certain types of pollutants. It relies on the aspiration of the ambient air in a dehumidification system with a heating of the micro-balance lowered to $30^{\circ} \mathrm{C}$ (which considerably limits the volatilization of the compounds). This last method is at present largely used in the networks monitoring the air quality in France (after the reform of the particle measurement method adopted on 1st January 2007). About $80 \%$ of the stations of the air quality monitoring network are endowed with this technology (Airparif, 2008). This new sampling procedure triggered an increase in the pollution episodes in certain regions and a greater concern of the public authorities against this type of pollution.

\subsection{New norms set up in France in $\mathbf{2 0 1 2}$}

The air quality monitoring is subject to three regulation levels (European, national and local).

3.2.1. Before the year 2008, the PM10 and PM 2.5 particles was not subject to an information and/or alert threshold in the European directives, being however regulated by limit values (daily and annual for PM10 and annual for PM 2.5) (Directive no. 1999/30/CE/22 April 1999). In France, beginning with October 2007, a ministerial memo (Ministry of Ecology and Sustainable Development and 
Arrangement, 2007) has been addressed to the prefects in order to create an information and alert system for the PM10 pollution peaks on the basis of the recommendation thresholds proposed by the Superior Council of Public Hygiene of France (Superior Council of Public Health - CSHPF) on 6 June 1996 (information thresholds beginning with $80 \mu \mathrm{g} / \mathrm{m} 3$ and alert threshold beginning with $125 / \mathrm{m} 3$ on mobile average/ 24 hours) (CSHPF, 1996) (Prefect's Decision /2nd September 2008 for the Maritime Seine).

3.2.2. Beginning with the year 2008, the European Directive of 21st May 2008 on ambient air quality and cleaner air for Europe restates the same values applicable since 2005 for PM10 $(40 \mu / \mathrm{m} 3)$ per civil year. For the particles whose diameter is under $2.5 \mu$ (PM 2.5), it defines a limit value of $25 \mu \mathrm{g} / \mathrm{m} 3$ for 2015, applicable starting with 2009 with a margin of $+20 \%$.

3.2.3. Beginning with 1st January 2012, the thresholds for the fine particles are lowered in France (decree no. 2010-1250 / 21st October 2010 translating the directive 2008/50/CE of the EU Parliament and Council of 21st May 2008); the information level goes down from 80 to $50 \mu \mathrm{g} / \mathrm{m} 3$ and the alert threshold moves from 125 to $80 \mu \mathrm{g} / \mathrm{m} 3$. The first consequence of this threshold lowering is the increase of the number of alert and the cases of information and recommendation threshold (for PM10) for sensitive people (Figure 4).

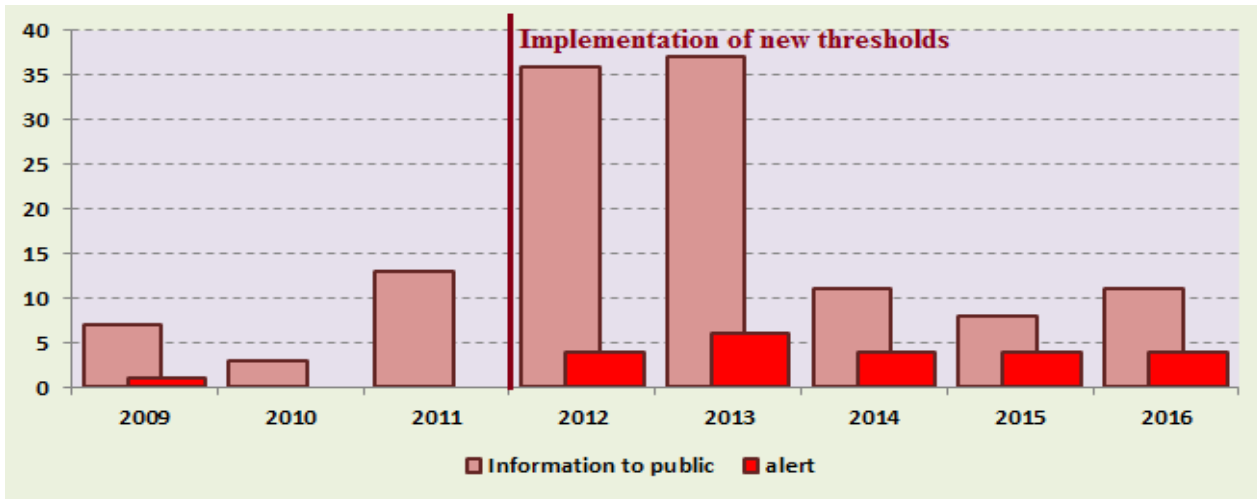

Fig. 4. Evolution of the number of alert days and information to the public in Paris (PM10) (Data: http://www.airparif.asso.fr/)

A more visible pollution because of the multiplication of alerts since 2012. The increase in particle pollution alerts in France arises first as a result of the change in measurement methods adopted in 2007 and 2012. This form of pollution at a second time is more important in view of states aids and its policy from several years to encourage the use of diesel (the French car fleet is $70 \%$ composed of diesel vehicles) and wood-fired heating (the use of wood heating is widespread in the country) (two highly polluting sources of energy). 
The pollution episode of December 2016 in France is a situation that cannot be described as exceptional, it has been favored by a cold anticyclonic winter weather that favors the predominance of stable situations.

The mobilization of the media and local elected representatives shows that this phenomenon is considered a new concern which implies urgent measures to protect the population against this scourge. A report of the health monitoring institute published in June 2016 estimates that the number of deaths caused by this form of pollution amounts to 48000 deaths.

The first direct consequence of the pollution of December 2016 is a significant increase in the implementation of the "alternating circulation" system. The second consequence is the introduction of a regulated circulation in the event of air pollution from 15 January 2017 (a graduated traffic sticker from 1 to 5 will be mandatory for all vehicles) and traffic will be in direct relation to the air quality recorded in the capital (https://www.certificat-air.gouv.fr/)

\section{REFERENCES}

1. Airparif, (2008). Synthèse des connaissances sur les particules en suspension dans l'air et des travaux d'airparif sur ces polluants. Pôle Études, 105 p.

2. Allen. G., Sioutas C., Koutrakis P., Reiss R., Lurmann F W., Roberts PT., (1997). Evaluation of the TEOM method for measurement of ambient particulate mass in urban areas, Journal of the Air and Waste Management Association, 47, 682-689.

3. Ayers G. P., Keywood M. D., Gras J. L., (1999). TEOM vs. manual gravimetric methods for determination of PM 2.5 mass concentrations, Atmospheric Environment, 33, 3717-3721.

4. Conseil Supérieur d'Hygiène Publique de France, Superior Council of Public Health (CSHPF) / le 6 juin 1996 (6 june 1996), Avis du 12 mai 1996 relatif au projet de directive européenne sur l'air ambient.

5. Corso M, Pascal M, Wagner V, Blanchard M, Blateau A, Cochet A, et al., (2015), Impact à court terme des particules en suspension (PM10) sur la mortalité dans 17 villes françaises, 2007-2010. Bull Epidémiol Hebd, (1-2):14-20. http://www.invs.sante.fr/beh/2015/1-2/2015_1-2_3.html.

6. Legrand, M. Puxbaum, (2007), H, Summary of the CARBOSOL project: Present and Retrospective State of Organic Versus Inorganic Aerosol over Europe, Journal of Geophysical Research, 112 (023), 1029.

7. Laurence P., Blachard M. Fabre P., Larrieu S., Borrelli D., Host D., Chardon B., Chatignoux E., Prouvost H., Jusot JF., Wagner V., Declerc Ch., Medina S., Lefranc A., (2009), Liens à court terme entre la mortalité et les admissions à l'hôpital et les niveaux de pollution atmosphérique dans neuf villes françaises, BEH Bulletin épidémiologique hebdomadaire, 5, 41-44.

8. Ministry of Ecology and Sustainable Development and Arrangement, Ministère de l'Écologie, du Développement et de l'Aménagement durables (2007), Circulaire relative à l'information du public sur les particules en suspension dans l'air ambient $12 \mathrm{p}$. 
9. Paolo. J., Sellegri. K., (2003), Les aérosols atmosphériques: impacts locaux, effets globaux, Revue Française des Laboratoires, 349, 23-34.

10. W. M. O., (1983) Report of the experts meeting on aerosols and their climatic effects, Geneva, WCP-55, ICSU, 65 p.

11. www.cnrs.fr/alpes (2007), L'origine surprenante de la pollution atmosphérique particulaire en composés carbonés, Communiqué de presse, Paris, 10st Decembre. 2007, 3 p.

12. Pascal M., de Crouy Chanel P., Corso M., Medina S., Wagner V., Goria S., et al., (2016), Impacts de l'exposition chronique aux particules fines sur la mortalité en France continentale et analyse des gains en santé de plusieurs scénarios de réduction de la pollution atmosphérique. Saint-Maurice : Santé publique France 158 p. http://invs.santepubliquefrance.fr/Dossiers-thematiques/Environnement-etsante/Air-et-sante/Publications. 